\title{
ELABORAÇ̃̃O DE MATERIAL DIDÁTICO PARA O ENSINO DE PORTUGUÊS COMO LÍNGUA DE ACOLHIMENTO: PARÂMETROS E PERSPECTIVAS*
}

Production of material for the teaching of Portuguese as host language: parameters and perspectives

\author{
Izabel Cristina Silva DINIZ (CEFET-MG $)^{1}$ \\ Júnia Moreira da CRUZ (CEFET-MG) ${ }^{2}$
}

\section{RESUMO}

O Brasil tem recebido refugiados e demais imigrantes de diversas partes do mundo. Ao penetrarem em outro cenário sociocultural, esses estrangeiros entram em contato com uma nova língua, que se torna instrumento no processo de integração social. Sendo esse o contexto de investigação, propomos uma discussão quanto à produção de material didático para esse público específico, bem como sobre o termo língua de acolhimento. Para tanto, apresentamos entrevistas com professores voluntários de língua portuguesa. Ademais, com esse estudo, buscamos identificar quais abordagens de ensino de língua são consideradas no processo de ensino-aprendizagem de português como língua de acolhimento. Os resultados apontam para um grande desafio a ser enfrentado.

Palavras-Chave: Língua de acolhimento, Material didático, Imigrantes, Refugiados

\section{ABSTRACT}

Brazil has received refugees and other immigrants from various parts of the world. When entering another socio-cultural scenario, these foreigners come into contact with a new language, which becomes for them an instrument in the process of social integration. In such context of research, this work proposes a discussion about the production of teaching material for this specific public, as well as about the term host language. For this purpose, we present interviews with volunteer teachers of Portuguese language. Furthermore, with this investigation, we identify which approaches of language teaching are considered in the teaching-learning process of Portuguese as host language. The results point to a great challenge to be faced.

Keywords: Host language, Teaching material, Immigrants, Refugees

\footnotetext{
* Pesquisa apresentada no XII Encontro de Português Língua Estrangeira e no $3^{\circ}$ Congresso de Português Língua Internacional, realizados na Universidade Federal Fluminense, de 14 a 16 de setembro de 2016.

${ }^{1}$ Centro Federal de Educação Tecnológica de Minas Gerais, Belo Horizonte, Minas Gerais, Brasil. ORCID: https://orcid.org/0000-0002-6648-7742; izabel.diniz@,hotmail.com

${ }^{2}$ Centro Federal de Educação Tecnológica de Minas Gerais, Belo Horizonte, Minas Gerais, Brasil. ORCID: https://orcid.org/0000-0002-9502-7446; juniamcruz@gmail.com
} 


\section{Considerações iniciais}

No atual cenário mundial, caracterizado por expressiva mobilidade, intercâmbios econômicos e culturais crescem substancialmente. Ao verificamos as trocas proporcionadas pela globalização e o viés mercadológico que integra esse processo, não podemos deixar de pontuar algumas impressões sobre determinados fenômenos, como, por exemplo, os impactos ambientais, a instabilidade econômica e a exclusão social. Diante disso, observam-se problemas humanitários relevantes, como o deslocamento de pessoas em estado de vulnerabilidade social.

Em se tratando de refugiados, a motivação para deixar seu país acontece, fundamentalmente, em razão da sobrevivência. Essas pessoas deslocam-se para salvar a vida ou para preservar a liberdade. $\mathrm{O}$ fato é que, neste limiar do século XXI, presenciamos expressivo contingente de pessoas dispersas involuntariamente em vários lugares do mundo. Dados do Alto Comissariado das Nações Unidas para Refugiados (ACNUR) ${ }^{3}$ revelam que há mais de 65 milhões de deslocados. Atualmente, comparando com a população mundial, 1 a cada 113 indivíduos é refugiado, deslocado interno ou solicitante de refúgio.

A Convenção de Refugiados de 1951 atesta que refugiados são aqueles que se encontram fora de seus lares em razão de perseguição por motivos de raça, religião, nacionalidade, opinião política ou participação em grupos sociais. Também são enquadrados nesse grupo os que abandonam suas terras em consequência de conflitos armados, violência generalizada e violação de direitos humanos.

Ao ACNUR, que age em parceria com instituições governamentais e não governamentais, cabe conduzir e coordenar ações internacionais para proteção de refugiados, bem como supervisionar as diretrizes adotadas pela Convenção de 51. No Brasil, os dados fornecidos pelo Comitê Nacional para Refugiados (CONARE) ${ }^{4}$ - órgão colegiado responsável por tomar decisões em matéria de refúgio registram 9.552 refugiados (dez./2016), de 82 nacionalidades, reconhecidos pelo Governo.

A legislação brasileira - lei 9474/97 - estabelece que essas pessoas disponham de proteção do Estado e permissão para obter documentos, trabalhar, estudar e exercer os mesmos direitos de qualquer cidadão estrangeiro legalizado. O ACNUR destaca o fato de o Brasil aceitar refugiados; contudo, constatase que é preciso conceber condições efetivas, em várias esferas, para que eles possam se integrar socialmente. Quanto a isso, Amado (2013) questiona

como o refugiado poderá sobreviver até obter essa condição do Ministério da Justiça, que demora em média oito meses para ser concedida? Seu visto de turismo expira em três meses. Sem documentos, ele não pode fazer nada: alugar casa, ter uma linha de celular, colocar os filhos na escola, ter um emprego. (AMADO, 2013, p.2)

Além dos refugiados, desembarcam no Brasil outros imigrantes em estado de miséria moral (AMADO, 2013), muitas vezes privados de direitos humanos elementares. É o caso de bolivianos,

\footnotetext{
${ }^{3}$ Disponível em: http://www.acnur.org/portugues/recursos/estatisticas/. Acesso em: 14 out. 2017.

${ }^{4}$ Disponível em: http:/www.acnur.org/portugues/recursos/estatisticas/dados-sobre-refugio-no-brasil/. Acesso em: 14 out. 2017.
} 
haitianos, colombianos, entre outros povos que chegam, não raro, sem recursos financeiros, em busca de melhores perspectivas de vida. Importante ressaltar que o governo brasileiro disponibiliza visto humanitário aos haitianos, vítimas do terremoto que devastou o país em 2010.

Em comum, os imigrantes citados - incluindo os refugiados - vivenciam mudanças significativas ao entrarem em contato com outro contexto sociocultural. Dialogar em uma nova língua torna-se necessidade indispensável, já que isso potencializa a integração e viabiliza o aperfeiçoamento das competências interpessoal, comunicativa e linguística.

Em relação à língua, por exemplo, Amado (2013, p.6) atesta que "embora o Brasil seja um país de imigrantes, está aquém de ter uma política de ensino do português como língua de acolhimento". É apropriado destacar que, no momento atual, as organizações não governamentais e as instituições religiosas têm prestado apoio aos refugiados e demais imigrantes, inclusive, no que se refere ao ensino de língua portuguesa. Prática que tem sido realizada tanto por professores com formação na área de Letras quanto por outros voluntários. Para Amado (2013),

ainda que o papel de voluntários não docentes ministrando português para os refugiados seja essencial em caráter emergencial, é inconcebível que um país que possui mais de 400 cursos de Letras e que forma cerca de 31.000 professores por ano (PAIVA, 2005) não possa criar um programa que contrate professores. (AMADO, 2013, p.6)

Nessa perspectiva, torna-se pertinente refletir sobre o ensino de português como proposta de acolhimento, pois a língua é fator primordial no processo de integração de imigrantes. O desenvolvimento da linguagem, de acordo com Rezende (2010), é a porta de compreensão e a forma de marcarmos nossa presença no mundo.

Diante do exposto, este trabalho busca (i) problematizar sobre o conceito de língua de acolhimento, (ii) propor uma discussão quanto à produção de material didático para refugiados e demais imigrantes em situação de miséria moral e (iii) verificar qual(is) abordagem(ns) são consideradas como mais apropriadas para a produção de material didático destinado ao ensino de português como língua de acolhimento. Para tanto, apresentamos entrevistas com professores voluntários que atendem esse público no Brasil.

\section{Língua de acolhimento e material didático}

Ao deixar suas raízes, em busca de sobrevivência, o refugiado experimenta o convívio com outras culturas. Nesse curso de interseções, mudanças significativas ocorrem em sua vida, a exemplo do contato com uma nova língua. No caso do Brasil, onde aprende o português, Rezende (2010) afirma que a principal preocupação do refugiado é a de sustentar um domínio básico do idioma, para que consiga lidar com as atividades cotidianas. Na mesma perspectiva, Cabete afirma que

de facto, o desconhecimento da língua poderá representar um obstáculo à comunicação com o Outro, ao conhecimento dos seus direitos e deveres enquanto actor social e criar 
uma desigualdade onde o imigrante se torna mais vulnerável. A barreira linguística leva da mesma forma ao afastamento daqueles que não o compreendem e a aproximar-se, naturalmente, de quem partilha os mesmos códigos linguísticos. (CABETE, 2010, p.58)

Segundo Grosso (2010), a língua de acolhimento vai além da noção de língua estrangeira ou segunda língua. Isso porque as crescentes trocas linguísticas e os diferentes contextos de ensinoaprendizagem promovem novas formas de se ver a educação em línguas. "O ensino das línguas insere-se atualmente num modelo de educação que acompanha as mudanças sociais, as questões étnicas e culturais e que tem como finalidade a reconstrução de uma sociedade mais justa, humana e intercultural" (ibidem, p.69).

Orientada para a ação, a língua de acolhimento tem um saber fazer que contribui para uma interação real, a vida cotidiana, as condições de vida, as convenções sociais e outras que só podem ser compreendidas numa relação bidirecional. (GROSSO, 2010, p.71)

Para Amado (2013), os aspectos linguísticos e extralinguísticos devem ser considerados nesse processo. É preciso cuidado ao lidar com um público que vivencia dificuldades numa sociedade que, não raro, discrimina e marginaliza. Rezende (2010) elenca ainda outras questões que permeiam os refugiados, tais como: as experiências traumáticas; a perda de referências, de laços afetivos e de uma vida produtiva.

No que tange ao uso da língua na vida contemporânea, Dell'Isola (2009) ressalta a importância de se desenvolverem as habilidades comunicativas, que viabilizam uma interação mais crítica e participativa no mundo. "É preciso investir em um ensino que promova a compreensão de como a linguagem se articula em ação humana sobre o mundo" (ibidem, p.99).

Dell'Isola (2009) argumenta, também, sobre a importância da inclusão de variados gêneros textuais em materiais didáticos. Segundo a referida autora, o uso de gêneros possibilita discussões sobre relações sociais, identidades e formas de conhecimento. Ademais, o emprego de diversificados gêneros textuais permite que o aluno observe, analise, interprete e aplique os recursos expressivos de uma língua estrangeira.

Diante disso, faz-se necessário pensar sobre o material didático que tem sido elaborado para atender os imigrantes em situação vulnerável. De acordo com Amado (2013), a maior parte das instituições faz uso de métodos intuitivos e há muito autodidatismo. Sendo assim, suspeitamos que haja a probabilidade de os conteúdos não se adequarem às necessidades de aprendizagem do público em foco. Além disso, há poucas produções no mercado, e as existentes são, relativamente, incipientes. Dessa forma, fica a cargo do professor ou da instituição que atende imigrantes a elaboração do material didático, como é o caso do ConectAdus ${ }^{5}$, desenvolvido pelo Instituto de Reintegração de Refugiados - Brasil.

Essa organização usou, durante algum tempo, livros de português como língua estrangeira cedidos por uma escola de idiomas cujo público alvo era estudantes em intercâmbio no Brasil. Após perceberem que o material não atendia às necessidades dos imigrantes e refugiados, e também devido às dificuldades

\footnotetext{
${ }^{5}$ Esta informação nos foi concedida em junho de 2015, quando entramos em contato com a coordenadora de ensino do ADUS.
} 
enfrentadas pelos professores voluntários em compreender o material, a equipe decidiu produzir o próprio material didático. Tarefa nada fácil considerando que a instituição tem um quadro de professores voluntários com diversificada formação profissional.

Outro exemplo de material didático elaborado para atender imigrantes em condição de vulnerabilidade social é a apostila Português do Brasil para Refugiados e Refugiadas: Pode Entrar. Esse material foi desenvolvido pelo Cursinho Popular Mafalda, com o apoio da Cáritas Arquidiocesana de São Paulo, e pode ser baixado gratuitamente no seguinte endereço: www.acnur.org/t3/portugues/recursos/publicacoes/. Ressaltamos que ambas as produções citadas são direcionadas ao ensino de português a refugiados. Sendo assim, as necessidades de aprendizagem dos demais imigrantes em situação de vulnerabilidade também seriam atendidas por esses materiais?

Todo material didático é elaborado de acordo com as concepções de linguagem, língua, ensino e aprendizagem adotadas por seus autores e/ou editores. Para melhor compreensão deste estudo, selecionamos três métodos de ensino para apresentá-los: comunicativo, intercultural e letramento crítico.

A abordagem comunicativa caracteriza-se por focalizar, principalmente, a interação propositada entre os sujeitos que estão aprendendo uma língua. Tal abordagem organiza as experiências de aprender em atividades e, especialmente, tarefas de interesse e/ou necessidade do aluno para que este possa usar a língua-alvo para realizar ações reais na interação com outros falantes-usuários dessa língua. Além disso, esta não toma as formas da língua descritas nas gramáticas como modelo suficiente para organizar as experiências de aprender outra língua, apesar de não descartar a possibilidade de criar na sala de aula momentos de explicitação de regras e de prática mecânica de usos dos subsistemas gramaticais, como o dos pronomes, as terminações de verbos etc. (ALMEIDA FILHO, 1993).

No contexto de ensino-aprendizagem de línguas estrangeiras, Mendes (2004) salienta que uma abordagem de ensino intercultural deve promover o diálogo de culturas. Isso significa que é preciso estar aberto para o outro e a experiência que ele traz; permitir um diálogo das nossas experiências com as do outro; juntarmo-nos ao outro para compreender o mundo; por fim, é preciso receber o outro sem receio de compartilhar medos, emoções, dúvidas. Para a mesma autora

a Abordagem Comunicativa Intercultural pode ser resumida como a força potencial que pretende orientar as ações de professores, alunos e de outros envolvidos no processo de ensino/aprendizagem de uma nova língua cultura, o planejamento de cursos, a produção de materiais e a avaliação da aprendizagem, com o objetivo de promover a construção conjunta de significados para um diálogo entre culturas. (MENDES, 2004, p.154)

O letramento crítico, por sua vez, é compreendido como uma abordagem que tem por objetivo problematizar as questões sociais, priorizando a heterogeneidade e a pluralidade de vozes (MOREIRA JÚNIOR, 2015; MATTOS e VALÉRIO, 2010). Como destacam Mattos e Valério (2010), tais estudos se debruçam sobre o caráter ideológico da comunicação e tem como objetivo principal o desenvolvimento da consciência crítica. Nessa vertente, a língua é vista como um instrumento de poder e transformação 
social de caráter idológico (MOREIRA JÚNIOR, 2015; MATTOS e VALÉRIO, 2010). Trabalhar em sala de aula sob a perspectiva do letramento crítico, como salienta Jordão, significa

construir com os alunos (e para nós mesmos) o entendimento de que ler é uma atividade, uma prática; é uma prática social, coletiva; é política, o que quer dizer que acontece de forma ideologicamente marcada por nossas vivências, nossas crenças, nossas comunidades interpretativas; é livre, mas depende do uso de procedimentos válidos ou compreensíveis dentro do contexto de leitura se quiser ser legitimada por ele. (JORDÃO, 2014, p.200-201)

Assim sendo, tais abordagens, nesse contexto, podem nos indicar caminhos para a produção de materiais didáticos destinados ao público em foco. Atualmente, esses métodos são, comumente, empregados no ensino de línguas.

\section{Metodologia}

A presente pesquisa trata-se de um estudo exploratório, com resultados qualitativos. O corpus consiste em entrevista realizada com quatro professores voluntários que atuam em uma instituição não governamental, localizada na cidade de Belo Horizonte $(\mathrm{BH})$. As entrevistas foram realizadas por meio de questionário enviado pelo GoogleDocs, no período de 14 a 22 de agosto de 2016, com o termo de consentimento livre e esclarecido anexo ao respectivo documento online. As seguintes perguntas compõem o referido questionário:

Quadro1 - Questionário aplicado aos participantes da pesquisa.

1. Informe sua formação acadêmica completa, incluindo graduação e titulações, área e universidade.

2. Há quanto tempo atua como professor de PLE?

3. Há quanto tempo trabalha com imigrantes em situação de vulnerabilidade social? público?

4. Qual é a nacionalidade de seus alunos? Onde você dá aula para esse

5. Como é dar aula para esse público?

6. Qual material didático utiliza? Considera o material adequado às necessidades de aprendizagem dos alunos? Por quê?

7. Você elabora material didático para o público em destaque? O que considera mais relevante na elaboração de material didático para esse público?

8. Qual abordagem de ensino considera mais apropriada na elaboração de material didático para os imigrantes?

9. Você acredita que o público em destaque tem especificidades importantes para serem consideradas durante a produção de material didático? Por quê? Quais seriam?

10. O que você compreende do termo língua de acolhimento?

\section{Análise dos dados}


Os quatro professores entrevistados são voluntários que atuam em uma ONG apoiadora de imigrantes na cidade de Belo Horizonte. Todos eles são estudantes de graduação ou de pós-graduação em Letras. Metade deles já possuía experiência no ensino de português como língua adicional ${ }^{6}$, antes de iniciar o trabalho com o público em destaque. Em relação à nacionalidade dos alunos atendidos pelos professores, é bem variada: haitiana ${ }^{7}$ (mais numerosa), colombiana, africana de diversos países, síria, venezuelana e outras.

Os materiais didáticos utilizados, por eles, são: o livro comercial Muito Prazer: fale o português do Brasil (2008), a verão digital da apostila Português do Brasil para refugiados e refugiadas: Pode Entrar (2015) e as unidades didáticas (UD) do $P P P L E^{8}$. Dentre esses, somente o segundo foi elaborado com a proposta de atender refugiados no Brasil.

O Portal do Professor de Português Língua Estrangeira / Língua Não Materna (PPPLE) é uma plataforma on-line, gratuita, cujo objetivo principal é oferecer à comunidade de professores e interessados em geral, materiais didáticos para o ensino e a aprendizagem do português como língua estrangeira/ língua não materna. Apesar de o portal oferecer material para grupos específicos, como é o caso de UD para ensino de português como língua de herança, ainda não se tem disponível UD destinada ao ensino de português como língua de acolhimento.

Já o livro Muito Prazer: fale o português do Brasil, Disal Editora, tem como público alvo alunos de qualquer nacionalidade que desejam aprender o português do Brasil. Na apresentação do livro não é possível perceber quem seriam esses alunos: adultos? estudantes universitários? imigrantes?

Os professores entrevistados declaram que fazem adaptações do conteúdo dos materiais citados, já que nenhum deles satisfaz totalmente as necessidades de aprendizagens dos imigrantes e refugiados por eles atendidos. Por essa razão, em algum momento, todos os professores produzem material didático, sendo comum adaptar o que já existe no mercado para o público-alvo.

Para os entrevistados as abordagens comunicativa, intercultural e letramento crítico são as mais apropriadas para a elaboração de material didático destinado ao ensino de português para imigrantes em vulnerabilidade social e moral. Somente um professor não soube dizer qual abordagem seria mais adequada. Entretanto, chama a atenção o fato de dois educadores afirmarem que o grupo, muitas vezes, demanda por realizar atividades estruturalistas.

Quadro 2 - Excertos das respostas à pergunta 8. Fonte: corpus da pesquisa.

\section{Professor $\mathrm{C}$ - alguns alunos se mostram céticos em relação à aula preparadas}

com essa abordagem. Muitos alunos, principalmente os haitianos, estão acostumados

\footnotetext{
${ }^{6}$ Consideramos, neste artigo, português língua adicional (PLA) como correspondente a português língua estrangeira (PLE). Não é objetivo, deste trabalho, discorrer sobre definição de PLA e PLE.

${ }^{7}$ Não há números exatos de quantos haitianos vivem na região metropolitana de $\mathrm{BH}$, calcula-se que haja aproximadamente cinco mil.

${ }^{8}$ Desde 2012. Disponível em: http://www.ppple.org/.
} 
a abordagens e métodos tradicionais de ensino de línguas. O que tento, portanto, e conciliar minhas práticas pedagógicas com as necessidades dos alunos e suas crenças a respeito do ensino de línguas no primeiro momento.

Professor $\mathrm{D}$ - percebo que muitos têm a necessidade de um aprendizado mais estrutural, tradicional. Então, tento ajustar.

(Grifo nosso)

Todos os entrevistados afirmam que para a produção de material didático é necessário considerar a condição de refugiado ou de imigrante. Como se verifica no quadro abaixo.

Quadro 3 - Excertos das respostas à pergunta 9. Fonte: corpus da pesquisa.

Pergunta 9. Você acredita que o público em destaque tem especificidades importantes para serem consideradas durante a produção de material didático? Por quê? Quais seriam?

Professor A - Sim, porque o processo de migração deles é diferente, assim como suas motivações para a aprendizagem do idioma.

Professor B - Definitivamente. É preciso entender que, apesar de classificá-los, muitas vezes, em um mesmo grupo (exemplo: imigrantes em situação de vulnerabilidade), nesse mesmo grupo, cada indivíduo tem sua história, suas necessidades, sua trajetória única até chegar aqui. É preciso que os materiais fujam de estereótipos, mesmo aqueles bem-intencionados, para que os estudantes tenham a oportunidade de mostrar quem são. Em geral, nenhum refugiado, por exemplo, gosta de ser visto unicamente como refugiado.

Professor C - Sim. Acredito que o Letramento Crítico é fundamental no ensino de línguas e, em especial, no ensino de PLAc. O fato de que o público está, quase sempre, em situação vulnerabilidade e foto de que está imerso em uma cultura nova fazem com que esse público tenha experiências que podem causar choque, desconforte e até trauma. As aulas de língua são ajudam o(a) imigrante faça parte da comunidade ativamente, tenha mais oportunidades de crescimento, conheça seus direitos e deveres enquanto cidadão, etc.

Professor D - Sim. Eles são imigrantes em situação de vulnerabilidade e, não raro, sem apoio de políticas públicas. Então, precisamos nos esforçar para contribuir para o empoderamento, bem como para integrá-los socialmente. Então, penso que o material didático deva contribuir. Considero primordial focar em aspectos da cultura brasileira, do trabalho, dos direitos. E, principalmente, acho fundamental fazê-los sentir parte dessa sociedade, para que se vejam como cidadãos. Daí a importância do letramento crítico também.

(Grifo nosso)

Isso reforça as considerações de Cabete (2010), quanto ela afirma que o imigrante é um adulto, que deseja desenvolver uma atividade laboral, que necessita da língua para comunicação, principalmente quando há a necessidade de usar a língua como instrumento de apoio à resolução dos problemas do dia a dia.

Língua de acolhimento é um conceito relativamente novo no cenário acadêmico brasileiro. Quanto a esse conceito, os professores voluntários disseram compreender que 
Quadro 4 - Excertos das respostas à pergunta 10. Fonte: corpus da pesquisa.

Professor A - É a área do conhecimento que se debruça sobre a questão do ensino de língua portuguesa para imigrantes vulneráveis, levando em consideração suas especificidades e necessidades.

Professor B - Ainda não vejo como algo que possa ser facilmente definido. O que sabemos é que não podemos acreditar que se ensina português para o público focalizado na pesquisa de vocês e um grupo de turistas ou imigrantes que vêm ao nosso país em condições mais privilegiadas. Eu acredito que o PLAc se dirija mais para questões de vulnerabilidade, mas, não somente entendendo vulnerabilidade como falta de dinheiro, mas, como falta de identidade, de reconhecimento por parte daqueles que os recebem.

Professor $\mathrm{C}$ - Acredito que o termo Língua de Acolhimento reconhece a importância do ensino de línguas na criação da identidade do sujeito que se encontra em situação de refúgio/imigração.

Professor D - Entendo este termo como uma forma de se compreender o ensino-aprendizagem de línguas de uma maneira mais holística, baseada em desafios, como os atuais, afinal, vivenciamos expressivas diásporas no mundo. Então, a língua, no caso a portuguesa, passa a ser fundamental no processo de integração. Mas é preciso ir além, é preciso formar cidadãos críticos dotados de direitos e deveres. Sem isso, os imigrantes correm o risco de ficarem à margem da sociedade e cada vez mais vulneráveis socialmente.

(Grifo nosso)

Como se pode perceber, as respostas sobre o que seja língua de acolhimento variam desde "área do conhecimento" a "forma de compreender o processo de ensino e de aprendizagem de uma língua". Portanto não há um consenso sobre a definição de língua como proposta de acolhimento para o grupo entrevistado. Ao contrário disso, verifica-se uma dificuldade na compreensão do que é denominado língua de acolhimento e de qual seu enquadramento teórico.

\section{Considerações finais}

Pensar em língua de acolhimento sugere um trabalho direcionado a um público de imigrantes em condição de vulnerabilidade social e moral, seja ele tido como refugiado ou não. Considerar essa questão, a nosso ver, é fundamental para o processo de ensino de uma determinada língua, já que esse grupo apresenta necessidades de aprendizagem diferentes das de estudantes universitário em intercâmbio, por exemplo. No caso de imigrantes, acreditamos que comunicar-se na língua alvo é primordial para a integração social do sujeito, portanto a habilidade oral deverá ser privilegiada, como atesta Cabete (2013).

Quanto à produção de material didático para refugiados e demais imigrantes em situação de miséria moral, há temas que serão mais produtivos. Quanto a isso, um dos participantes desta pesquisa pontua

Quadro 5 - Excerto resposta à questão 9. Fonte: corpus da pesquisa. 


\begin{abstract}
Professor B - É preciso entender que, apesar de classificá-los, muitas vezes, em um mesmo grupo (exemplo: imigrantes em situação de vulnerabilidade), nesse mesmo grupo, cada indivíduo tem sua história, suas necessidades, sua trajetória única até chegar aqui. É preciso que os materiais fujam de estereótipos, mesmo aqueles bemintencionados. Em geral, nenhum refugiado, por exemplo, gosta de ser visto unicamente como refugiado.
\end{abstract}

(Grifo nosso)

Os temas relacionados à cultura brasileira são recomendados para compor o material didático, mas é preciso, sem dúvida alguma, evitar estereótipos. No cenário atual, o material didático Pode Entrar serve de referência de temas interessantes para as aulas de português como língua de acolhimento. Sobre isso, Cabete (2010) sugere dois eixos fundamentais: a cultura e a cidadania.

Além disso, parece-nos significativo incluir textos autênticos diversificados no material didático, independente do nível de proficiência dos aprendizes, pois estes "traduzem uma forma de ser e de organização na sociedade" (GROSSO, 2007, apud CABETE, 2010, p.77)

$\mathrm{Na}$ opinião dos participantes desta pesquisa, as abordagens de ensino que devem ser ponderadas para a produção de material didático destinado ao ensino de português como língua de acolhimento, como já dito, são: letramento crítico, comunicativa e intercultural. Cada um dos métodos de ensino citados tem objetivo diferente: desenvolvimento da consciência crítica, desenvolvimento da competência comunicativa e desenvolvimento da capacidade de entender e gerenciar diferentes visões de mundo, respectivamente. Contudo tais abordagens são consideradas complementares (cf. MATTOS e VALÉRIO, 2010; MENDES, 2004), sendo perfeitamente possível associá-las, já que preveem uso de textos autênticos, valorização da autonomia, exploração da heterogeneidade linguístico-discursiva, centralidade nas necessidades de aprendizagem do aluno.

Concordamos com Cabete (2010) quando a autora defende que a abordagem comunicativa seria a mais recomendada para o ensino de língua de acolhimento. Isso porque a necessidade de comunicação dos aprendizes é imediata. Eles necessitam se comunicar para realizar as atividades diárias, bem como para conseguir trabalho. Nessa perspectiva, acrescentamos que, por evidenciar os valores e as necessidades de uma coletividade, a língua é ferramenta de acesso aos bens socioculturais. "Acredito na formação de um cidadão crítico e autor de seus discursos na língua adicional, e não apenas um conhecedor dos aspectos linguísticos estruturais dessa língua" (BIZON, 2013, p.172).

Em toda discussão acerca de material didático, concluímos que não existe material perfeito, e que o professor deve utilizá-lo conforme a necessidade de aprendizagem da turma. Por essa razão, em algum momento, todos os professores entrevistados produzem material didático, sendo recorrente adaptar o que já existe no mercado editorial para o público-alvo. Consideramos o material Pode Entrar como referência devido à qualidade e por ser, realmente, destinado às necessidades de aprendizagem de refugiados recémchegados ao país. Parece-nos que esse material é um bom exemplar de língua como acolhimento no contexto brasileiro. Apontamos apenas algumas ressalvas quanto aos enunciados das produções textuais 
escritas, os quais não incluem o contexto de produção e de recepção, bem como o pouco uso de textos autênticos na composição do material. No entanto, na seção Complementação Pedagógica há a indicação de alguns textos autênticos para utilizar-se em sala de aula.

Quando se trata de língua de acolhimento, tem-se como referência a experiência portuguesa. Diferente de Portugal, onde o Governo desenvolve desde 2001 programas de atendimento aos imigrantes e refugiados, inclusive com oferta de ensino de língua, no Brasil, mais especificamente em BH, somente as instituições religiosas e não governamentais têm assumido esse papel. Tal fato justifica a dificuldade de investigar as práticas de ensino dos professores voluntários, pois uma parte não tem interesse acadêmico no assunto e, muitas vezes, as instituições que atendem esse público não aprovam qualquer tipo de pesquisa. Diante da experiência portuguesa, percebe-se que é possível criar políticas públicas que atenda ao grupo em destaque.

Os imigrantes em condição de vulnerabilidade social também querem melhores perspectivas de vida. Alguns deles têm se interessado por estudar em universidades brasileiras. Diante disso, uma questão se impõe: o ensino de um idioma como língua de acolhimento se inscreve aos primeiros meses de permanência em um país? Ou seja, após dois anos de estada no Brasil, por exemplo, o imigrante deve ainda realizar cursos de português como língua de acolhimento? Uma vez vivendo no Brasil, na condição de refugiado, até que nível de proficiência o ensino será conduzido como língua de acolhimento? Um curso de nível intermediário para imigrantes, que estejam se preparando para o ingresso em uma universidade pública brasileira, deve pautar-se no ensino de português como língua de acolhimento? Só é possível pensar em língua de acolhimento para os imigrantes recém-chegados ao país, nos primeiros níveis de proficiência?

Diante dessas questões, ressaltamos a importância de continuar investigando o ensino de português como língua de acolhimento. Um tema tão recente e atual na história deste país.

\section{Referências Bibliográficas}

ACNUR - Alto Comissariado das Nações Unidas para Refugiados. Estatísticas. Disponível em: http://www.acnur.org/portugues/recursos/estatisticas/. Acesso em: 14 out. 2017.

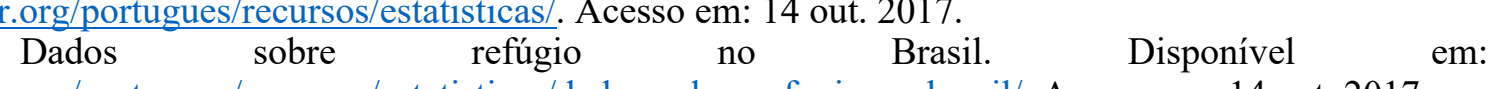

http://www.acnur.org/portugues/recursos/estatisticas/dados-sobre-refugio-no-brasil/. Acesso em: 14 out. 2017.

ADUS - Instituto de Reintegração do Refugiado - Brasil. Disponível em: http://www.adus.org.br/. Acesso em: 20 ago. 2016.

ALMEIDA FILHO, J. C. P. 1993. Dimensões comunicativas no ensino de línguas. Campinas, SP: Pontes.

AMADO, R.S. 2013. O ensino de português como língua de acolhimento para refugiados. Revista da Sociedade Internacional Português Língua Estrangeira, Edição 7, Ano 4, n.2. Brasília.

BIZON, A. C. C. 2013. Narrando o exame Celpe-Bras e o convênio PEC-G: a construção de territorialidades em tempos de internacionalização. Tese de Doutorado em Linguística Aplicada. Universidade Estadual de Campinas. CABETE, M. A. C. S. S. 2010. O processo de ensino-aprendizagem do português enquanto língua de acolhimento. Dissertação de Mestrado em Língua e Cultura Portuguesa. Universidade de Lisboa.

DELL'ISOLA, R. L. P. 2009. Gêneros textuais em livros didáticos de português língua estrangeira: o que falta? In DIAS, R.; CRISTÓVÃO, V.L.L (orgs.) O livro didático de língua estrangeira: múltiplas perspectivas. Campinas: Mercado de Letras, p.99-120. 
FERNANDES, G. R. R., FERREIRA, T. S. B e RAMOS, V. L. 2008. Muito prazer: fale o português do Brasil. Barueri, SP: Disal.

GROSSO, M. J. R. 2010. Língua de acolhimento, língua de integração. In: Horizontes de Linguística Aplicada. Brasília, v.9, n.2, p.61-77.

JORDÃO, C. M. 2014. Birds of different feathers: algumas diferenças entre letramento crítico, pedagogia crítica e abordagem comunicativa. In TAKAKI, N. H.; MACIEL, R. F. (orgs.). Letramentos em terra de Paulo Freire. Campinas: Pontes editores.

MATTOS, A. M. A. e VALÉRIO, K. M. 2010. Letramento crítico e ensino comunicativo: lacunas e interseções. RBLA, Belo Horizonte, v. 10, n.1, p. 135-158. Disponível em: http://www.scielo.br/pdf/rbla/v10n1/08.pdf. Acesso em: 14 out. 2017.

MENDES, E. 2004. Abordagem comunicativa intercultural: uma proposta para ensinar e aprender língua no dialogo de culturas. Tese de Doutorado em Linguística Aplicada. Universidade Estadual de Campinas. MOREIRA JÚNIOR, R. S. 2015. Português como língua adicional e letramento crítico: análise das experiências com alunos estrangeiros. Anais do International Congress of Critical Applied Linguistics. Brasília, Brasil $\quad-\quad$ 19-21 outubro. $<$ http://www.uel.br/projetos/iccal/pages/arquivos/ANAIS/PRATICA(S)/PORTUGUES\%20COMO\%20 LINGUA\%20ADICIONAL\%20E\%20LETRAMENTO\%20CRITICO.pdf>. Acesso em: 26 mar. 2017. OLIVEIRA, J. F. et al. 2015. Português do Brasil pra refugiados e refugiadas: Pode Entrar. São Paulo. Material digital. Disponível

em: http://www.acnur.org/t3/fileadmin/Documentos/portugues/Publicacoes/2015/Pode Entrar.pdf. Acesso em: 15 out. 2017.

PPPLE. Unidades didáticas. Disponível em: http://www.ppple.org/. Acesso em: 4 set. 2016.

REZENDE, P. S. 2010. A constituição identitária de refugiados em São Paulo: moradias na complexidade do ensino-aprendizagem de português como língua estrangeira. Tese de Doutorado em Linguística Aplicada e Estudos da Linguagem. Pontifícia Universidade Católica de São Paulo.

Izabel Cristina Silva Diniz graduated in Languages from the Pontifical Catholic University of Minas Gerais (2005) and master's degree in Language Studies from the Federal Center of Technological Education of Minas Gerais CEFET-MG (2013). She is currently a PhD student in Language Studies at CEFET-MG and has experience in teaching Literature and Portuguese Language.E-mail: izabel.diniz@hotmail.com

Júnia Moreira da Cruz graduated in Social Communication from the University Center of Belo Horizonte (2003). She is currently a master's degree student in Language Studies at the Federal Center of Technological Education of Minas Gerais. She has experience in Portuguese as additional language and as host language. E-mail: juniamcruz@gmail.com 